\title{
Influência do capital intelectual na avaliação de desempenho aplicada ao setor hospitalar
}

\author{
The influence of intellectual capital in performance evaluation: \\ a case-study in the hospital sector
}

Carlos Alberto Grespan Bonacim ${ }^{1}$

Adriana M aria Procópio de A raújo ${ }^{1}$

${ }^{1}$ Departamento de Contabilidade, Faculdadede Administração, Economiae ContabilidadedeRibeirão Preto, USP. Av. Bandeirantes 3900, M onteAlegre. 14040-900 Ribeirão Preto SP.carlosbonacim@usp.br
Abstract This paper contributes to public institutions with theadaptation of a performanceevaluation tool based on private companies. The objective is to demonstrate how the impact of an educational activity might be measured in theeconomic value added for the society of a public university hospital. The paper was divided in four parts, despite the introductory and methodological aspects and the final remarks. First, the hospital sector is explained, specifically in the context of the public university hospitals. Then, the definitions, the nature and measure of the intellectual capital are presented, followed by the disclosure of the main economic performance evaluation models. Finally, an adapted model is presented, under theapproach of the valuebased management, considering adjustments of the return and the respective investment measures, showing the impacts of the intellectual capital management and the education activity on the economic result of those institutions. The study was developed based on a methodology supported by a bibliographical research, using a comparative method procedure in the descriptive modality. At last, it is highlighted the importance of accountability for the society regarding the use of public resources and how this study can help in this way.

Key words Intellectual capital, Public management, H ealth management, Performance evaluation
Resumo Esteestudo contribui com a adaptação, para as entidades públicas, de uma ferramenta de avaliação de desempenho sedimentada nas empresas privadas. 0 objetivo é demonstrar como pode ser mensurado o impacto da atividade de ensino no valor econômico agregado por um hospital universitário público à sociedade. Para tanto, o texto foi dividido em quatro partes, além dos aspectos introdutórios, metodológi cos e das considerações finais. Inicialmente, será contextualizado o setor hospitalar, mais especificamente os hospitais universitários públicos. Logo após, serão apresentadas as defini ções, a natureza emensuração do capital intelectual, seguidas da demonstração dos principais modelos avaliação de desempenho econômico. Finalmente, será apresentado um model o adaptado, sob o enfoque da gestão baseada no valor, propondo ajuste nos indicadores de retorno e do respectivo investimento, demonstrando os impactos da gestão do capital intelectual e da atividade de ensino no resultado econômico de tais instituições. 0 estudo foi elaborado por intermédio de uma metodologia consubstanciada em uma pesquisa bibliográfica, sob o prisma do método de procedimento comparativo descritivo. Ressalta-se, por fim, a importância da prestação de contas para a sociedade quanto ao uso do recurso público.

Palavras-chave Capital intelectual, Gestão pública, Gestão da saúde, Avaliação de desempenho 
Introdução

Desde a década de noventa, a gestão pública no Brasil está passando por grandes mudanças incentivadas por reivindicações sociais que pedem maior eficiência, transparência e eficácia na aplicação dos recursos públicos.

A crença de quea melhoria das condiç̧ões sociais do país passa pela participação ativa da sociedade civil, nos processos de discussão edetomada de decisão relacionados às questões e políticas públicas, determinou o desenvolvimento desta pesquisa, que visa contribuir com uma visão mais integrativa da empresa pública ede seu relacionamento com o cidadão (contribuinte).

Todas as em presas necessitam de fundos para desenvolver suas atividades operacionais. As três formas legais básicas de organização de uma empresa são: (1) firma individual - uma empresa de propriedade uma única pessoa que a opera visando ao seu próprio lucro; (2) sociedade consisteem dois ou mais proprietários dirigindo conjuntamente um empreendimento, com fins lucrativos; (3) sociedade anônima - entidade empresarial intangível, criada por lei, cujos donos são os acionistas, em vista de seu patrimônio na forma de ações ${ }^{1}$.

Já as entidades públicas são as que produzem produtos ou serviços que visam ao bem-estar da sociedade [...], as entidades públicas governamentais são todas as do quadro de administração dire ta eindireta da U nião, do estados, do distrito federal e dos municípios, as autarquias e as fundações instituídas e mantidas pelo poder público².

Desta maneira, os cidadãos (contribuintes) que disponibilizam os recursos para o Estado podem ser equiparados aos proprietários ou acionistas das empresas privadas. Assim, a sociedade pode cobrar das entidades públicas governamentais uma atuação mais parecida com a de organizações privadas e exigir, como eles, eficiência na aplicação dos recursos públicos.

Um relatório gerado com a avaliação de uma empresa privada é capaz de influenciar as percepções dos proprietários ou acionistas acerca da empresa e suas perspectivas futuras.

Da mesma forma, a avaliação do desempe nho econômico pode representar uma importante ferramenta para promover a transparência na gestão pública eampliar o grau de accountability (o conceito de accountability adotado neste estudo éo de prestação de contas por meio de instrumentos que facilitem a transparência [...] relatórios que façam com que o cidadão possa fazer comparações com resultados privados e, as- sim, sentir-se confortável ao ver que a gestão pública está sendo eficiente no gasto dos recursos públicos $\left.[\ldots]^{2}\right)$.

0 presente trabalho procura acompanhar 0 que existe na gestão contemporânea de empresas, efetuando a devida adequação às condições das entidades públicas. N esse contexto é que se justifica a adaptação da teoria de mensuração do capital intelectual com a finalidade de servir como ferramenta para a prática gerencial de avaliação do desempenho de empresas públicas.

Esse tema vem assumindo um papel de destaque em todo mundo, exigindo dos gestores novos desafios na busca contínua da eficiência e eficácia das atividades. 0 acelerado avanço tecnológico ea especial ização constante dos profissionais despontam de forma desproporcional aos recursos financeiros. A qualidade associada à utilização racional dos recursos deve ser o novo desafio.

Desta forma, são estabelecidos alguns indicadores para avaliação. Naturalmente, a discussão sobre o desempenho econômico-financeiro dos hospitais já vem de longa data, mas alguns fatos contribuíram para que esta questão alcançasse as proporções atuais, em especial os custos da assistência médica e a incorporação crescente e progressiva de tecnologia não substitutiva.

Além disto, o novo século trouxeconsigo uma nova era econômica - a era do conhecimento - e, com ela, um problema emergiu: como mensurar os fatores econômicos intangíveis que afetam o valor dos ativos de uma empresa?

Assim, uma empresa administra não só seus ativos tangíveis, mas também seus ativos intangíveis. Desta forma, os indicadores de retorno sobre ativo, calculados para uma empresa em que os ativos intangíveis representem uma parcela significante dos ativos totais, estariam ignorando uma parcela importante do cálculo, desta maneira mostrando índices de desenvolvimento diferentes dos reais.

N esse cenário em quea tecnologia e a economia avançam rapidamente, defende-se que o capital intelectual de uma empresa tem determinado cada vez mais o seu valor econômico. Entenda como capital intelectual de uma empresa o seu conhecimento, experiência, especialização e diversos ativos intangíveis (em vez do tangível, físico e financeiro) ${ }^{3}$.

Considerando o interesse em contribuir para a melhoria do processo de gestão de avaliação de investimentos realizados pela sociedade(Estado) em hospitais universitários públicos, pretendese, com esse estudo, responder à seguinte questão orientadora de pesquisa (problema de pes- 
quisa): diante desse contexto, quais indicadores poderiam ser mais adequados? Existem vários modelos destinados à apuração do valor de uma empresa, erespectivosindicadores. N aturalmente, a contabilidadetradicional (apoiada nos princípios contábeis) requer ajustes para atender à gestão baseada em valor, dentre eles a depreciação, impostos, investimentos estratégicos e em pesquisa e desenvolvimento.

O capital intelectual engloba, além da capacidade intelectual humana, os nomes de produtos, marcas, fatores como liderança tecnológica, capacitação de funcionários, agilidade no atendimento aos clientes, etc., características estas de terminantes nas intuições hospitalares, em especial nos hospitais universitários ${ }^{4}$.

Assim, em consonância com a questão estabelecida, 0 objetivo deste trabalho é demonstrar como pode ser mensurado o impacto da atividade de ensino no valor econômico agregado por um hospital universitário público à sociedade.

\section{Aspectos metodológicos}

A metodologia empregada neste trabal ho foi a de pesquisa bibliográfica. Apesar de assumir a necessidade de uma pesquisa empírica, 0 assunto ainda é incipiente. A pesquisa bibliográfica é necessária para se conhecer previamente o estágio em que se encontra 0 assunto a ser pesquisado, independentemente de a qual campo do conhecimento pertença ${ }^{5}$.

Assim, a pesquisa bibliográfica se constitui num "conjunto de conhecimentos reunidos nas obras tendo como base fundamental conduzir 0 leitor a determinado assunto eà produção, [...] e utilização" ${ }^{6}$. Portanto, 0 apanhado da bibliografia em conjunto com comparações qualitativas agrega valor à discussão existente - formação de um futuro construto ou modelo.

\section{Os hospitais universitários públicos}

Os hospitais universitários (HU) caracterizam-se como sendo centros de saúde públicos vinculados a cursos de graduação em medicina. São conhecidos como hospitais-escola pois servem de laboratórios paraosestudantes. Alguns são extremamente conceituados e oferecem tratamento de al ta qualidade sem qualquer custo para o paciente.

Um hospital universitário é entendido, antes de tudo, como um centro de atenção médica de alta complexidade, pois: (i) tem importantepapel no atendimento médico dealta complexidade; (ii) apresenta forte envolvimento em atividades de ensino e pesquisa relacionada ao tipo de atendimento médico dispensado; (iii) atrai alta concentração de recursos físicos, humanos e financeiros em saúde; (iv) exerce um papel político importante na comunidade que está inserido, dada sua escala, dimensionamento, orçamento e custos?.

As características dos $\mathrm{HU}$ fazem com queseus custos sejam ainda mais elevados, quando comparados a hospitais não universitários de alta tecnologia, tais como atividades docente-assistenciais e serviços básicos de saúde, quando sua estrutura é constituída para oferecer atividades de alta tecnologia.

Em 2001, esses hospitais universitários públicos foram responsáveis por aproximadamente $9 \%$ dos leitos, $12 \%$ das internações e $24 \%$ dos recursos do SUS destinados ao pagamento de internações. Tal concentração reflete maior dimensão média e envolvimento significativo com a alta complexidade ${ }^{8}$. Estes responderam, no mesmo período, por cerca de $50 \%$ das cirurgias cardíacas, $70 \%$ dos transplantes, $50 \%$ das neurocirurgias e $65 \%$ dos atendimentos na área de malformações craniofaciais 9 .

O SU S reembolsa os hospitais com basenuma tabela de preços única para cada procedimento. Os hospitais são reembolsados por esses valores, não importando o tempo de permanência no hospital ou os custos reais incorridos com os pacientes.

Percebe-se que este sistema de reembolso, teoricamente, não admiteineficiência, exigindo dos HU um al to grau de eficácia e eficiência na gestão dos recursos escassos. Todavia, os hospitais de ensino encontram-se debilitados ${ }^{10}$ por serem mais dispendiosos, dado que incorporam atividades de ensino, pesquisa e extensão e por serem um referencial em tecnologia deponta, quando écrescente a exi gência do governo e da soci edade pela racionalização dos gastos e despesas.

Assim, os HU dificilmente poderiam ser competitivos ${ }^{7}$ em um sistema de reembolso por serviço e seriam pouco atrativos aos planos de seguro médico. A tendência é que se mantenham custeados pelo setor público, com boa parte dos serviços prestados de forma gratuita ou subsidiados. Assim, os HU têm diante de si o desafio de prover atenção à saúde a uma crescente população idosa e arcar com os custos derivados, equacionando a relação entre disponibilidade e acesso versus financiamento adequado.

Para que os HU possam fazer tais investimentos, éimportantequehaja recursos. Elestêm 
basicamente duas maneiras de acumular recursos: (1) gastar menos do que ganham, isto é, acumular lucro ou superávit; (2) conseguir recursos extras do governo através da aprovação de projetos. Qualquer um dos casos exige que o HU mostre sua eficiência em utilizar os recursos e o retorno que ele tem provido à sociedade.

Por isso, é importante mostrar o valor econômico que o hospital agrega à sociedade. Assim como as empresas privadas devem mostram 0 retorno proporcionado ao acionista, as entidades públicas devem mostrar o retorno à sociedade.

\section{A puração dos custos de ensino em um hospital universitário}

A universidade pode ser considerada uma organização com multiprodutos ou com produto único; de uma maneira geral, três produtos principais Ihe são atribuídos: ensino, pesquisa e extensão ${ }^{11}$. A pesar de ser caracterizada como uma instituição com multiprodutos, tem-se o ensino de graduação e pós-graduação como seu maior produto ${ }^{12}$.

N este contexto, uma Comissão de Financiamento da Educação M édica da Association of
American M edical Colleges realizou, em 1972, estudos de custos em doze escolas médicas, sendo seis públicas e seis privadas. Esta comissão definiu, sem a realização de estudos empíricos, um percentual de $35 \%$ de dedicação dos profissionais ao ensino. Todos os demais custos das atividades de suporte foram alocados com base neste percentual ${ }^{10}$.

A apuração de custos em hospitais universitários tem sido tema de debates na literatura científica. Outro estudo internacional concluiu que os hospitais que incorporam atividades de ensino possuem os custos elevados em $20 \%$ quando comparados com hospitais apenas assistenciais ${ }^{13}$.

Por sua vez, Hosek ePalmer ${ }^{14}$ consideram que os hospitais de ensino podem ter custos menores que os demais hospitais em decorrência dos estudantes serem substitutos de médicos. Porém, o contrário pode ocorrer devido a diferenças de mix de serviços, técnicas médicas ou qualidade do atendimento. N estecaso, éal egado que médicos residentes e internos pedem exames e utilizam materiais em demasia e os hospitais de ensino enfatizam excessivamente equipamentose técnicas sofisticadas. A metodologia escolhida foi a do custo incremental com base no trabalho de Jones e Korn ${ }^{15}$ (Quadro 1).

Quadro 1. M etodologias para apuração de custo do ensino em hospitais universitários.

\begin{tabular}{|l|l|l|l|}
\hline \multicolumn{1}{|c|}{$\begin{array}{c}\text { Conceito de } \\
\text { custos }\end{array}$} & \multicolumn{1}{|c|}{ Custo incremental } & \multicolumn{1}{c|}{ Divisão proporcional } & \multicolumn{1}{c|}{ Custo total } \\
\hline Pergunta & $\begin{array}{l}\text { Num abiente onde o ensino } \\
\text { (pesquisa) e a assistência médica } \\
\text { são conduzidos em conjunto, } \\
\text { como os custos poderão aumentar } \\
\text { se o programa de ensino for } \\
\text { adicionado? }\end{array}$ & $\begin{array}{l}\text { Num ambiente onde o ensino } \\
\text { (pesquisa) e a assistência médica são } \\
\text { conduzidos em conjunto, qual é a } \\
\text { participação proporcional dos custos } \\
\text { institucionais totais que podem e } \\
\text { devem ser atribuídos para o ensino? }\end{array}$ & $\begin{array}{l}\text { Qual é o custo dos recursos } \\
\text { mínimos para } \\
\text { desenvolvimento do ensino? } \\
\text { (Identificação do capital } \\
\text { intelectual da atividade de } \\
\text { ensino e pesquisa). }\end{array}$ \\
\hline $\begin{array}{l}\text { Componente } \\
\text { de custo }\end{array}$ & $\begin{array}{l}\text { Custos diretos do tempo gasto } \\
\text { pelo corpo docente no ensino de } \\
\text { alunos da área médica, suporte } \\
\text { direto e indireto de programa de } \\
\text { educação. }\end{array}$ & $\begin{array}{l}\text { Custos diretos do tempo gasto pelo } \\
\text { corpo docente no ensino de } \\
\text { estudantes da área médica e atividades } \\
\text { relacionadas ao ensino; suporte direto } \\
\text { e indireto do programa de educação } \\
\text { de estudantes da área da saúde. }\end{array}$ & $\begin{array}{l}\text { Custos institucionais mais } \\
\text { atividades de estudo e } \\
\text { assistência médica } \\
\text { considerada essencial para o } \\
\text { ensino. }\end{array}$ \\
\hline $\begin{array}{l}\text { Alocação de } \\
\text { custos das } \\
\text { atividades } \\
\text { conjuntas }\end{array}$ & $\begin{array}{l}\text { Custos alocados somente na } \\
\text { extensão em que eles seriam } \\
\text { inferiores se o programa de ensino } \\
\text { do aluno de saúde não existisse. }\end{array}$ & $\begin{array}{l}\text { Uma participação proporcional dos } \\
\text { custos totais nas atividades de } \\
\text { produtos conjuntos. }\end{array}$ & $\begin{array}{l}\text { Os custot totais de todas as } \\
\text { atividades de produtos } \\
\text { conjuntos. }\end{array}$ \\
\hline
\end{tabular}


A escolha entre as tipologias depende da missão do hospital universitário (HU) em que será apurado o custo. Assim, considerando a primeira alternativa a realização apenas de atividades assistenciais no HU e a segunda, a realização tanto de atividades assistenciais como de ensino, a diferença entre estas duas alternativas seria considerada o custo do ensino.

0 referido trabal ho recomenda o método de entrevistas para segregar os custos conjuntos. Este método estima as funções de custo com base em análises e opiniões sobre os custos e seus direcionadores, obtidas de vários departamentos da organização através de entrevistas estruturadas com os profissionais envolvidos diretamente com as atividades. Para os autores, a credibilidadedo método depende da reunião de conhecimentos específicos, como a acurácia das estimativas efetuadas pelo pessoal que fornece os dados (entrevistas).

Este método não se limita a identificar o volume de tempo da mão de obra consumida em determinada atividade. Por meio das entrevistas, também se pode determinar como os custos que não sejam de pessoal devem ser distribuídos pelos centros de custo das atividades.

Da atividade deensino, decorrem diversosfatores com impacto nos custos dos hospitais universitários. Alunos e residentes podem utilizar mais recursos mesmo quando não executam ne nhum procedimento como, por exemplo, luvase máscaras para observar a manipulação de um medicamento quimioterápico. Ou ainda, dosar um medicamento incorretamente, necessitando do preparo de outra dosagem. A instituição pode adquirir um número maior de microscópios, por exemplo, para as atividades de ensino.

\section{Capital intelectual}

O conceito decapital intelectual teveseu início na década deoitenta, mais especificamenteem 1986, quando Sveiby publicou o livro The Know-H ow Company, com indicações de como gerenciar ativos intangíveis, na Suécia. Em 1991, na Escandinávia, a empresa Skandia instituiu o cargo de diretor de capital intelectual, a ser ocupado por Edvinsson ${ }^{16}$.

O capital intelectual pode ser entendido e definido a partir de pontos distintos de observações. 0 capital intelectual deve ser dividido em quatro categorias de ativos: (1) de mercado; (2) humanos; (3) de propriedade intelectual e (4) de infraestrutura ${ }^{17}$. Contudo, existe uma outra pro- posição de divisão do capital intelectual em três dimensões: (1) competência dos empregados; (2) estrutura interna e (3) estrutura externa ${ }^{18}$.

Neste contexto, o conhecimento só pode ser criado por indivíduos ${ }^{19}$. A organização precisa apoiar os indivíduos criativos e lhes proporcionar contextos para a criação do conhecimento.

Além disso, o capital intelectual é um capital não financeiro representando a lacuna oculta entre o valor de mercado e o valor contábil ${ }^{4}$, sendo, portanto, a soma do capital humano e do capital estrutural. Conforme os autores, muitos gestores consideram o capital intelectual como sendo o recurso mais importante para a criação de valor econômico das empresas, já que o seu gerenciamento através de métodos de mensuração tende a se tornar relevante para o desenvolvimento das estratégias de sucesso das organizações.

Existem medidas para o gerenciamento do capital humano em forma de indicadores. Estes se relacionam com a reputação dos empregados da companhia junto a empresas de colocação de empregados, anos de experiência na profissão, taxa de empregados com menos de dois anos de experiência, satisfação dos empregados, proporção dos empregados dando novas idéias e sugestões e proporção implementada e valor adicionado por empregado e por unidade monetária de salário ${ }^{20}$.

Deste modo, éimprescindível que as organizações reconheçam, identifiquem, invistam e mensurem a importância das pessoas, da capacidade humana e do uso da informaçãa ${ }^{21}$.

Esta mensuração e o consequente monitoramento sistemático fornecem informações, proporcionando aos gestores condições para a tomada de decisão estratégica dentro da empresa. Então, 0 capital humano está relacionado aos conhecimentos (explícito etácito) ${ }^{22}$ úteis para as empresas que têm, em sua estrutura, pessoas e suas equipes, assim como sua capacidade de renovação.

Diversos modelos podem ser utilizados na mensuração decapital intelectual. Alguns conhecidos atualmente são enumerados: (1) o método Skandia de Edvinsson; (2) o método Sveiby; (3) o método do navegador do capital intelectual de Stewart; (4) o método Q deTobin e(5) o método $M$ arket-to-Book . Contudo, existem métodos de mensuração alternativos ${ }^{23}$.

Muitas das informações divulgadas a respeito das empresas demonstram em várias situações que o valor das empresas no mercado - e por mercado entenda-se bolsa de valores - apresenta montantes superiores a seu valor contábil. Esse valor, o contábil, é apurado mediante o va- 
Ior patrimonial demonstrado no balanço contábil, sugerindo certa fragilidade da contabilidade em mensurar tal valor.

Uma das maneiras de esclarecer a diferença entre o valor das ações demonstrado no balanço patrimonial eo valor de mercado das empresasé a ocorrência da entrada de novos valores. Esses podem ser oriundos da capacidadetécnica deseu corpo de funcionários em gerar benefícios futuros denominados de capital intelectual.

\section{A mensuração do capital intelectual}

Para determinar o valor do capital intelectual, é necessário analisar o seu componente mais importante, que é o ativo humano. Por sua vez, os gastos com recursos humanos, quando são sacrifícios incorridos pela empresa na obtenção de serviços com o objetivo de obter benefícios futuros, podem ser classificados como ativos. Assim, esses gastos devem ser tratados como despesas nos períodos em que resultam benefícios; se tais benefícios relacionam-sea um tempo futuro, eles devem ser tratados como ativos ${ }^{24}$.

Com efeito, há três critérios para a existência de um ativo: (1) possuir potencial de serviços futuros; (2) ser mensurável em termos monetários e (3) estar sujeito à propriedade ou controle da entidade contábil, conformeo estudo deH endriksen eVan Breda supracitado. 0 critério principal é o potencial de serviços futuros: se não se espera que um objeto preste serviços futuros, então não pode ser um ativo.

0 objeto deve ser mensurável em termos monetários, o denominador comum dos relatórios financeiros. Assim, um objeto pode possuir um potencial de serviços futuros mas, a não ser que seus serviços futuros possam ser medidos em termosmonetários, não se podetratá-lo como um ativo. 0 recurso deve estar sujeito ou à propriedade ou ao controle da entidade e o elemento-chave deste critério é a noção de controle. Os relatórios fornecidos atualmente pela contabilidade financeira não retratam determinadas realidades das empresas, uma vez que o valor contábil das ações está abaixo de seu valor de mercado.

A contabilização e consequente divulgação do valor do capital intelectual nas demonstrações contábeis apresentam duas dificuldades distintas: 0 desenvolvimento tanto dos métodos de mensuração do valor da força de trabalho e de criação de uma empresa, quanto dos meios de amortização dos investimentos da empresa em seus recursos humanos.
Entretanto, ocorre a prevalência de programas como cursos de orientações para novos empregados, programas para executivos, programas de capacitação de empregados, prêmios por metas atingidas, participações nos lucros se objetivos forem alcançados, etc. Estes gastos são feitos com expectativa de futuro retorno, uma vez que fazem com que os empregados aumentem o potencial deserviçose, consequentemente, de resultados. Pode-se verificar a aceitação por parte de contadores em registrar o capital humano como sendo um ativo, mas fazendo objeções a sua exposição com base no fato de que ele não pode ser objetivamente medido.

A prática contábil atual trata todos os gastos com desenvolvimento de recursos humanos como despesa em vez de ativo. Essa convenção resulta numa mensuração distorcida do retorno de uma organização sobre seus investimentos. Nesse caso, deixa de refletir a realidade econômica da organização. A aplicação do recurso do conhecimento nas organizações gera benefícios intangíveis, além dos tangíveis, ea contabilidade está procurando uma maneira de mensurar esse valor, para cumprir com eficácia sua função primária, ou seja, fornecer informações relevantes a seus usuários para a tomada de decisões.

$\mathrm{Na}$ sociedade do conhecimento, muitos princípios, conceitos e normas contábeis devem ser reavaliados, como, por exemplo, o princípio do registro pelo valor original - custo de aquisição e devidosajustes: depreciação - pacificamenteaceita para avaliar os ativos da empresa, não se aplica aos ativos intelectuais. Por exemplo, um sistema de custos contábil que considera apenas o custo do material e da mão de obra não responde adequadamente a essa nova realidade. N esse estudo, observa-se que muitos dos componentes do custo de um produto ou serviço (hospitais) se referem aos ativos intelectuais.

Existem empresas que mantêm em seus quadros de funcionários cientistas e pesquisadores. Esses indivíduos são pagos pela empresa e sua contraprestação é a realização de investimentos em construção do conhecimento. A contabilização desse caso deveria ser feita na conta (plano de contas contábil) "ativo diferido", para ser amortizada posteriormente, à medida que são recuperadas, por meio da realização de receitas oriundas dessas pesquisas.

Apesar de grande repercussão patrimonial dos ativos intelectuais, a contabilidade não os tem levado em consideração como faz com os demais ativos, na avaliação patrimonial e divulgação de suas informações. Entretanto, várias 
iniciativas vêm ocorrendo no sentido de buscar definir uma metodologia adequada para mensurar este novo tipo de capital.

\section{0 modelo de mensuração} do capital intelectual do Grupo Skandia

Esse modelo apresenta como característica fundamental a classificação do capital intelectual como passivo. Portanto, difere dos demais em sua essência de fundamentação teórica em classificação de ativos e passivos.

A Figura 1 ilustra as condições propostas para o modelo: (a) o capital intelectual é um passivo, não um ativo e (b) o capital intelectual representa informação adicional (independente das informações econômico-financeiras).

A Figura 2 mostra os instrumentos propostos de $N$ avegador Skandia ${ }^{4}$, o qual utiliza indicadores para cinco áreas distintas de focos.

Percebe-se que, dentro de cada foco, são estabelecidos indicadores, permitindo avaliar o desempenho; sendo assim, as combinações dos cinco focos acabam em relatórios diferentes e dinâmicos. Os focos utilizados na representação do navegador são áreas nas quais a empresa direciona sua atenção. Desses focos, origina-se 0 valor do capital intelectual no âmbito de seu ambiente.

\section{O model o deavaliação do capital intelectual de Stewart}

Sob outro prisma, o estudo de Stewart ${ }^{25}$ segmenta sua metodologia, quando da avaliação ( não mensuração) do capital intelectual, em quatro grupos: (1) medidas do todo; (2) medidas do capital humano; (3) medidas do capital estrutural e (4) medidas do capital de clientes, chamado de navegador do capital intelectual. Cumpreser ressaltado que suas aplicações são analíticas, pela possibilidade de visualizar, de forma simultânea, diversas dimensões do capital intelectual.

A Figura 3 ilustra o navegador do capital intelectual ${ }^{25}$ queutiliza uma medida geral denominada de razão valor de mercado/valor contábil e três indicadores para cada um dos itens do capital humano, estrutural e do cliente.

O navegador apresenta escalas nos eixos, mas não demonstra valores. $\mathrm{Na}$ prática, pode-se definir tais escal as de maneira que as metas fossem alocadas às extremidades, onde 0 eixo cruza 0 círculo. Assim, de acordo com a posição em cada escala, estarão sendo evidenciados os resultados atuais, dentro do que se deseja al cançar.

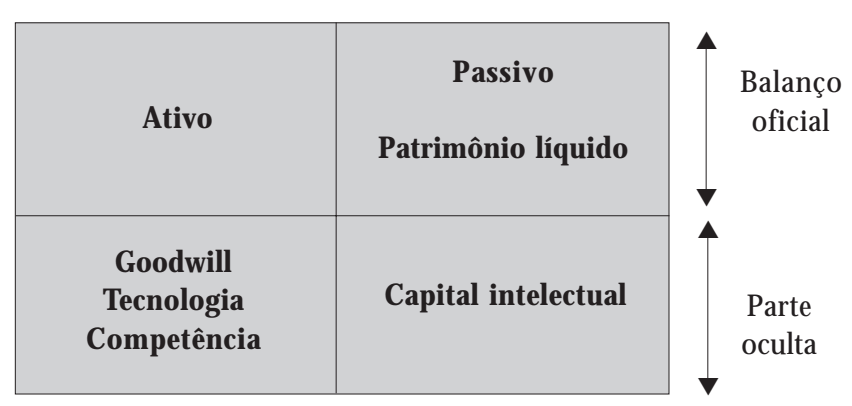

Figura 1. Estrutura conceitual do modelo.

Fonte: adaptado deEdvinsson eM alone ${ }^{4}$.

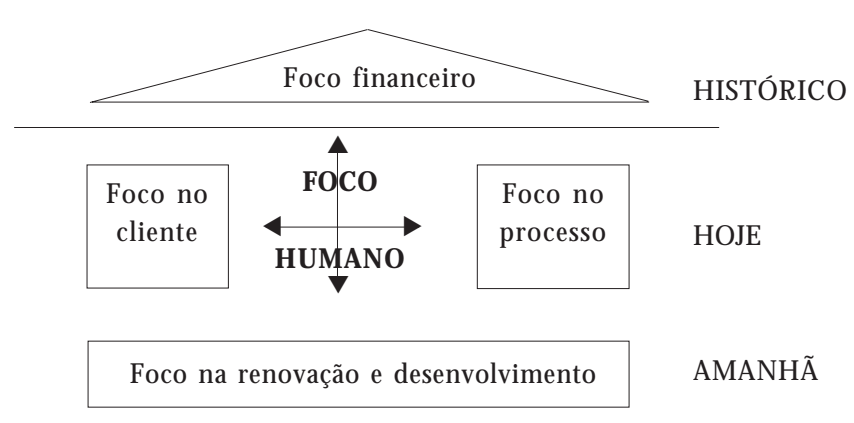

Ambiente operacional

Figura 2. Navegador Skandia.

Fonte: Edvinsson e M alonet.

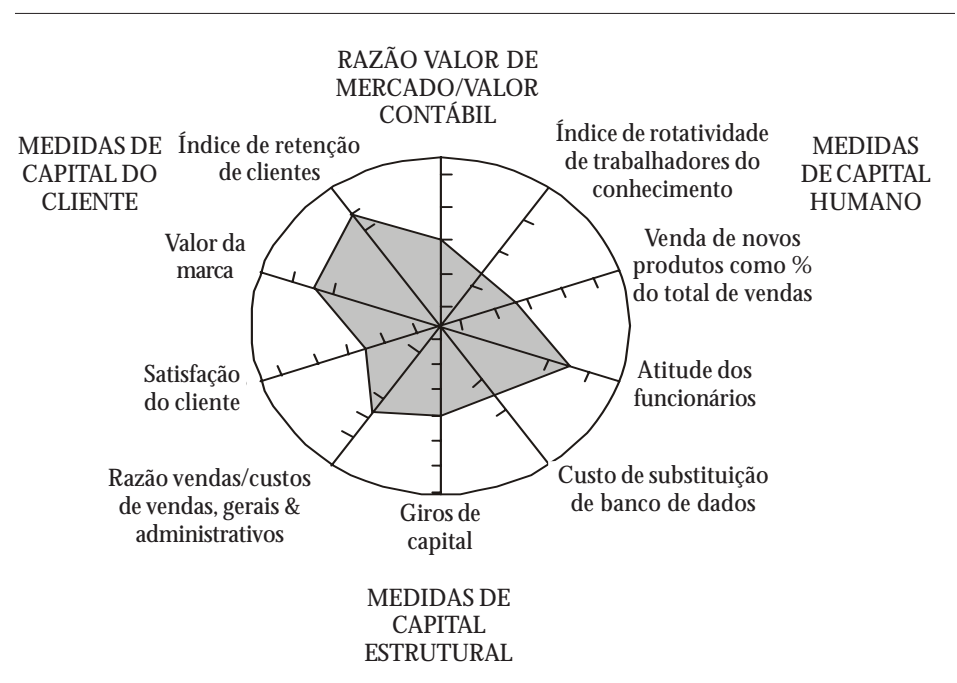

Figura 3. Navegador de Stewart.

Fonte: Stewart 25 . 


\section{O índice do capital intelectual}

Assim, propor o cálculo de um indicador para a mensuração do capital intelectual parece ser mais apropriado do que a utilização de modelos específicos para cada empresa: a comparabilidadee a facilidadena aplicação explicam. Assim, os autores sugerem o cálculo do índice do capital intelectual organizacional.

De acordo com os autores, durante a elaboração da fórmula, procurou-se identificar um conjunto básico deíndices, aplicável a qualquer instituição, com as mínimas adaptações. Assim sendo, chegou-se a seguinte fórmula: capital intelectual organizacional $=\mathrm{i} \mathrm{C}^{1}$, onde: $\mathrm{C}=$ valor monetário do capital intelectual; $i$ = coeficientede eficiência.

$O$ valor de $C$ é obtido de uma relação que contém os indicadores mais representativos de cada área de foco, avaliados monetariamente, excluindo os que pertencem mais propriamente ao balanço patrimonial. Estes indicadores referem-se ao exercício social.

Desta forma, podem representar alguns indicadores adequados4: (1) receitas resultantes da atuação em novos negócios; (2) investimento no desenvolvimento de novos mercados; (3) investimento no setor produtivo e no desenvolvimento de novos canais; (4) investimento em tecnologia da informação (TI) aplicada a vendas, serviço e suporte; (5) investimento no suporte, serviço e capacitação de clientes; (6) despesas com clientes não relacionadas ao produto ou serviço; (7) investimento no desenvolvimento da competência dos empregados; (8) capacitação especialmente direcionada aos empregados que não trabalham nas instalações da empresa; (9) investimento em capacitação, comunicação (e suporte) direcionados aos empregados temporários de período parcial ou integral; (10) upgrades no sistema e (11) investimentos na identificação da marca (logotipo, nome), novas patentes e direitos autorais.

Por sua vez, o coeficiente de eficiência do capital intelectual (i) é obtido por meio de indicadores mais representativos de cada área de foco expressos em porcentagens, quocientes, índices, complementa o estudo de Edvinsson e M alone. Estes parâmetros referem-se ao presente, nesse caso, expressos em pontos percentuais: (1) participação no mercado; (2) índice de satisfação dosclientes; (3) índicedeliderança; (4) índicede motivação; (5) índice de investimento em P\&D/ investimento total; (6) índice de horas de capacitação; (7) desempenho/meta de qualidade; (8) retenção de empregados e (9) eficiência administrativa/receitas.
Por fim, a média aritmética dos índices permite colocá-los em uma porcentagem única. $\mathrm{A}$ medida decapital intelectual éem função da quantidade deinvestimentos, medidosmonetariamente, realizados nos elementos quepodem ser mensurados objetivamente. Para isto, o modelo de gerenciamento do capital intelectual deve levar em consideração queo valor da organização provém da interação entre capital humano, estrutural eainda capital de clientes.

Embora o capital intelectual tenha seu reconhecimento conceitual explícito por órgãosinternacionais como o International Accounting Standards Committee (IASC), o Financial Accounting Standards Board (FASB) e a Securities Exchange Comission (SEC), não existe um modelo padrão para a divulgação do capital intelectual.

\section{M odel os de avaliação de desempenho econômico-financeiros}

As avaliações de organizações ou negócios dependem, em grande parte, das expectativas futuras de desempenho. Assim, o valor de uma empresa pode ser determinado através de um dos modelos de avaliação de empresas, mas a aplicação de uma simples equação ou metodologia pode não ser considerada suficiente.

Em qualquer abordagem deavaliação de uma empresa, sempre existeum propósito específico. A seguir, são discutidas as mais conhecidas medidas de avaliação utilizadas.

Os modelos baseados no balanço patrimonial se propõem a determinar o valor de uma empresa pela estimativa de mensuração de seus ativos. Esses métodos consideram o valor deuma empresa basicamente pelo valor explícito em seu balanço patrimonial. Determinam o valor deum ponto de vista estático; entretanto, não contemplam a possível evolução da empresa no futuro, incorporando o conceito de valor do dinheiro no tempo.

0 custo corrente ${ }^{26}$, cujo objetivo básico consiste em reconhecer e evidenciar os efeitos da variação específica dos recursos manuseados pela empresa, atenua al guns impactos da variação geral de preços da economia. Já o custo históri$\mathrm{CO}^{27}$ possui diversas limitações pelo simples fato de que o método decorre de a avaliação ser baseada em valores passados (ocorridos) e não em expectativas futuras de resultados.

Por sua vez, os modelos baseados na demonstração do resultado procuram analisar o desempenho de empresas multiplicando sua capacida- 
de de produção anual (ou suas receitas anuais) por uma taxa, conhecida como múltiplo. Neste contexto, um dos problemas desse método é que diferentes momentos de vendas implicam diferentes avaliações e ainda que as características de mercado em que atua cada empresa implicam diferentes potenciais de riqueza futura.

Além disso, o termo goodwill pode ser definido operacionalmente como o resíduo existente entre a soma dos itens patrimoniais mensurados individualmente e 0 valor total da empresa ${ }^{28}$. Assim, goodwill pode ser considerado como um excesso de valor em um processo de avaliação. Então, os modelos baseados no goodwill procuram determinar o valor da empresa através de uma estimativa que combina o valor de seus ativos líquidos adicionados a um ganho de capital proveniente do valor de futuros lucros.

Já os modelos baseados no fluxo de caixa procuram determinar o valor de uma empresa pela estimativa dosfluxos decaixa que devem ser gerados no futuro e então descontam esses valores a uma taxa condizente com o risco do fluxo. São modelos muito aceitos no mercado de consultoria e também amplamente citados e divulgados na bibliografia que versa sobre avaliações de ativos e avaliações empresariais. Sendo assim, o valor de uma empresa é o valor presente de seus fluxos de caixa previstos ao longo de sua vida ${ }^{29}$. Os modelos baseados no fluxo de caixa têm sido mais utilizados, dada a conclusão do aspecto pouco científico dos modelos anteriormente apresentados.

Já o Economic Vallue Added (EVA ${ }^{\circledR}$ - marca registrada da Stern Stewart) ${ }^{30}$ é utilizado para calcular a riqueza criada em determinado espaço de tempo; busca exatamente o cálculo da rentabilidade real de um capital aplicado. Trata-se de um indicador do valor econômico agregado, permitindo aos gestores e investidores, de uma forma geral, avaliarem com clareza se o capital empregado num determinado negócio está sendo bem aplicado ou não.

Um conceito muito relacionado ao do EVA ${ }^{\circledR}$ é o do M arket Value Added ou MVA ${ }^{\circledR}$, outra marca registrada da Stern Stewart. O MVA éum indicador que mede a criação de valor de uma empresa em relação aos recursos atribuídos ao negócio, em termos de mercado, ou seja, a diferença entre o valor de mercado da empresa e o capital investido. 0 MVA ${ }^{\circledR}$ mede a geração de valor de uma empresa em relação aos investimentos realizados.

Percebem-se, no contexto atual, al guns fatos, como 0 acentuado distanciamento entre 0 valor de mercado e o valor contábil das empresas e 0 alto teor de intangibilidade no valor real das empresas. Portanto, nas avaliações, não há como prescindir decerta dose de subjetividadena definição do valor de uma empresa, tomando-se a premissa de que alguns modelos se baseiam em resultados esperados obtidos do comportamento do mercado.

Avaliação de desempenho econômico em entidades públicas:

considerações preliminares

A avaliação de desempenho ${ }^{31}$ deveter indicadores que meçam, entre outras coisas: (1) eficácia: em que grau o produto (ou serviço, no caso dos hospitais) atende aos padrões estabelecidos consideradas as demandas de usuários e clientes; (2) eficiência: em que grau o produto (ou serviço) está sendo produzido a um custo mínimo e (3) qualidade: em que grau o produto (ou serviço) éadequado ao uso pelo usuário (cliente ou cidadão).

Além disso, entende-se que a avaliação de desempenho também faz parte de um processo ${ }^{32}$ em quese busca eficácia e eficiência. Desta forma, qualquer avaliação de desempenho não tem outro propósito senão o de buscar a eficácia empresarial, nesse contexto entendida como a competência em obter continuidadeem um ambiente dinâmico e de cumprir com sua missão.

Nesse sentido, inexistem quaisquer diferenças entre o processo deavaliação de desempenho entre as empresas do setor privado e demais organizações públicas, sem fins lucrativos.

N ormalmente as empresas privadas prestam contas, de forma espontânea, dos "resultados físico-operacionais" em um relatório complementar ao relatório da administração conhecido como relatório de atividades. Nesse relatório, expõe-se aos acionistas dados agregados e indicadores como giro de estoques, prazo médio de pagamento, prazo médio de recebimento, giro do ativo total, giro do ativo permanente, produtividadee qualidade, etc.

Ainda segundo o estudo de Olak, a prestação de contas no setor público é feita com base nas informações geradas pelos demonstrativos contábeis convencionais, pelo balanço social epor meio de um relatório de avaliação de resultados e desempenhos (relatório deatividades) ediretamente por meio dos sistemas orçamentários (empenho).

Em uma analogia, no setor privado, os acionistas usam os dados financeiros e econômicos (eficiência) publicados pela empresa para avaliar sua situação financeira e decidir se compram, 
vendem ou mantêm suas ações. 0 cidadão era visto (até então) pelo setor público como apenas um contribuinte, o equivalente a um cliente no setor privado. Ele (cidadão) não necessitava de uma detal hada prestação de contas.

Isso significa quea entidade pública deve prestar contas à sociedade tal qual empresas privadas devem prestar contas para o acionista. Assim, quando se pensa em calcular o valor econômico agregado por uma entidade pública, devese pensar no valor adicionado para a sociedade, ou seja, deve-se calcular a quantidade de valor econômico que a entidade agrega à sociedade.

Proposição de ajustes no modelo de aval iação de desempenho econômico para hospitais universitários sob o enfoque da gestão baseada em valor (GBV)

Feita as considerações acerca dos modelos de mensuração do capital intelectual, sob o enfoque da avaliação econômico-financeira tradicional, a atividade de ensino representa um custo adicional, influenciando a atratividade econômica de um hospital universitário.

O EVA ${ }^{\circledR}$ ou VEA (valor econômico agregado) pode ser determinado analiticamente ${ }^{33}$ por: VEA $=($ ROI-WACC $) \mathrm{x}$ investimento, onde: ROI é 0 retorno sobre investimento eo WACC (Weighted Average Cost of Capital) é o custo médio ponderado do capital (CM PC).

Para tanto, o ROI écalculado de acordo com a seguinte expressão: ROI = lucro operacional/ investimento.

Por sua vez, o WACC é calculado de acordo com a seguinte expressão: $W A C C=K i \times p_{1}+K e$ $x p_{2}$, onde: $K_{i}$ éo custo do capital de terceiros eo $\mathrm{K}_{\mathrm{e}}$ é o do capital próprio e $\mathrm{p}_{1}$ e $\mathrm{p}_{2}$ as respectivas proporções (\%).

Já a apuração do VEA exige algumas "adaptações" ${ }^{34}$, por exemplo, a apropriação de gastos com Pesquisa e Desenvolvimento ( $P \& D)$, normalmente lançados como despesa do período, diminuindo o resultado de forma distorcida, já que são investimentos em produtos e processos que trarão benefícios (receitas) no futuro.

Dessa forma, na gestão baseada em valor, esses gastos devem ser considerados investimentos, representados por ativos diferidos, devendo ser periodicamente amortizados. A apropriação da despesa passa a ser feita a partir da comercialização efetiva do produto.

Além disso, são propostos outros ajustes contábei $s^{35}$, como o da exclusão das despesas finan- ceiras no lucro operacional (decisões de financiamento), do diferimento de impostos, do reconhecimento de eventuais contingências, em que o problema está em como reconhecer incertezas de eventos futuros; na gestão baseada em valor, o importante é que a contingência seja reconhecida pelo critério do valor presente, entreoutros.

Contudo, existem algumas críticas ${ }^{36}$ à gestão baseada em valor e ao EVA ${ }^{\oplus}$, em especial relacionadas a sua aplicação em empresas em capital intelectual. 0 modelo apresentado a seguir evidencia ajustes relacionados aos custos incrementais da atividade de ensino e ao tratamento de investimentos pertinentes ao capital intelectual. Segundo tais autores, outra crítica relacionada ao EVA ${ }^{\oplus}$ refere-se aos "numerosos" ajustes necessários para a sua efetiva aplicação.

Entretanto, o valor intangível da empresa advém de diversos fatores que a contabilidade não reconhece, relacionados, como, por exemplo: (1) a organização interna da empresa; (2) o relacionamento com funcionários; (3) a condição de mercado e (4) a localização. Todas essas situações apresentam características de difícil mensuração contábil. Embora definir o goodwill de maneira justa e coerenteseja subjetivo, proceder a um ajusteinterferindo no processo de avaliação objetivando alcançar à realidade da empresa passa a ser relevantee, em alguns casos, extremamente necessário.

Assim, deve-se considerar a proposição do modelo EVA ${ }^{\circledR}$ e seus ajustes como a proposição um modelo de gestão baseada em valor, ou seja, não se trata apenas de uma métrica (mensuração), mas de um modelo de gestão que deve ser ajustado para a realidade das empresas, no caso, hospitais universitários.

Cumpre ser ressaltado que o modelo propõe ajustes nos indicadores de retorno e dos respectivos investimentos, mas mantém fixo o custo médio ponderado do capital (CM PC).

Trata-se de uma abordagem analítica da atratividade dos investimentos e com os ajustes: Iucro operacional $_{\mathrm{a}}=$ lucro operacional ${ }_{\mathrm{t}}+$ custo $_{\mathrm{da}}$ atividade de ensino e pesquisa, ou seja, sem os efeitos da atividade de ensino e de pesquisa; investimento $_{\mathrm{a}}=$ investimento $_{\mathrm{t}}$ - investimento correspondente ao capital intelectual (competência e tecnologia), ou seja, sem os efeitos dos investimentos em capital intelectual, tem-se o ROI ${ }^{\prime}$ ou 0 retorno sobre investimentos para a atividade assistencial, exclusivamente. Daí: ROI $=$ lucro operacional a / investimento a. $E$, assim, têm-se: $\mathrm{VEA}_{\mathrm{a}}=\left(\right.$ ROI $\left.{ }_{\mathrm{a}}-\mathrm{WACC}\right) \times$ investimento $_{\mathrm{a}}$

Portanto, com a mensuração da variação “VEA $=V E A_{t}-V A_{a}$, poderão ser demonstra- 
dos os impactos da atividade de ensino no resultado econômico da instituição.

\section{Consideraçõesfinais}

0 estudo procurou analisar a importância do reconhecimento dos investimentos em competência e tecnologia e seus respectivos custos incrementais, quando do tratamento de indicadores de desempenho.

0 objetivo deste artigo era 0 de demonstrar como pode ser mensurado o impacto da atividade de ensino no valor econômico agregado por um hospital universitário público à sociedade. Assim, foi feita revisão bibliográfica sobre 0 assunto e desenvolveu-se um modelo com o intuito de capturar tais impactos.

0 cálculo do presente valor econômico agregado à sociedade pelo hospital universitário público pode servir como referência para outros estudos, em especial estudos de aplicação do modelo teórico desenvolvido (construto). Ressalta-se que as conclusões delineadas neste estudo não podem ser generalizadas a todos os hospitais universitários públicos, pois as características culturais da entidade, sua relação com a universidade, o grau de desenvolvimento econômico esocial da região, etc. são fatores determinantes na condução das políticas assistências promovidas.

Contudo, a medida de valor desenvolvida neste trabal ho representa uma importante contribuição enquanto ferramenta de avaliação de desempenho pelo fato de incorporar o conceito decusto deoportunidade. Esta permiteuma análise mais segura do "quanto" do investimento público é devolvido para a sociedade.

Espera-se quetal medida de valor econômico tenha a capacidade demonstrar o potencial das entidades públicas na prestação de serviço que agregue valor, tal qual serviço privado, pois as medidas de avaliação de desempenho convencionais (lucro e suas variações) não consideram o custo de oportunidade do capital investido, sendo que para as entidades públicas, um parâme tro para o custo de oportunidade é a taxa Sistema Especial de Liquidação e Custódia (SELIC), taxa que remunera a dívida pública do Estado brasileiro.

Quando o governo altera o valor da taxa SELIC, automaticamenteafeta o custo do capital a ele confiado pela sociedade. A medida de valor proposta tem a sensibilidade de demonstrar os impactos proporcionados pelas políticas econômicas no valor econômico agregado pelas entidades públicas.

Assim, um aumento na taxa básica de juros aumenta o custo de oportunidade do capital investido pela sociedade, exigindo maior eficiência operacional (medida pelo resultado econômico operacional) das entidades públicas, como acontece no setor privado.

Com efeito, pôde-se verificar por meio do referencial bibliográfico que os hospitais universitários possuem alta concentração de investimentos em competência e tecnologia, até então desprezados pela contabilidade tradicional no quesito mensuração.

A gestão baseada em valor, mesmo com dificuldades relacionadas ao processo de implantação - em especial a resistência cultural e os inúmeros ajustes criticados por alguns autores parece ser a mais indicada. Os investimentos em tecnologia e a especialização constante dos profissionais são demandados de forma desproporcional aos recursos financei ros obtidos.

Desta forma, a avaliação de desempenho, pelo modelo adaptado, permite demonstrar a relação entreo investimento em capital intelectual (competência e tecnologia) e os custos "gerados" (atividades de ensino e pesquisa). Se os investimentos gerarem custos inferiores aos benefícios, será corroborada a atratividadeeconômico-financeira da empresa ( sob a perspectiva da gestão baseada em valor), além de sinergia dos recursos e alto desempenho. Senão, trará subsídios para que os gestores possam reordenar suas políticas estratégias, em especial as de investimento eoperacionais em tempo oportuno.

As variáveis propostas para o cálculo do valor econômico agregado à sociedade podem ser aprimoradas com o desenvolvimento de estudos que incorporem variáveis representativas das condições demográficas e derenda da região atendida pelo hospital universitário público.

Um último ponto a se destacar éa questão da aproximação da gestão pública e da gestão privada. Cabe então à sociedade cobrar do governo esta transparência em sua gestão. E a academia tem muito a contribuir, especialmente trazendo ferramentas de avaliação de desempenho que aproxime a gestão pública da sociedade. 


\section{Colaboradores}

CAG Bonacim eAM P Araújo participaram igualmente de todas as etapas da elaboração do artigo.

\section{Referências}

1. Gitman LJ. Princípios de administração financeira. 7a ed. São Paulo: Harbra; 1997.

2. Slomski V. Controladoria e governança na gestão pública. São Paulo: Atlas; 2005.

3. Klein DA. A gestão estratégica do capital intelectual: recursos para a economia baseada em conhecimento. São Paulo: Qualitymark; 1999.

4. Edvinsson L, Malone MS. Capital intelectual. São Paulo: Makron Books; 1998.

5. Santos JA, Parra Filho D. M etodologia científica. São Paulo: Futura; 1998.

6. Fachin O. Fundamentos de metodologia. São Paulo: Atlas; 1993.

7. Medici AC. Hospitais universitários: passado, presente e futuro. Rev. Ass. M ed. Bras. 2001; 47(2):149156.

8. Hospitais Universitários e de ensino no Brasil: desafios e soluções. Linha Direta UnB no 46/2002. [acessado 2004 ago 15]. Disponível em: http:// www.unb.br/reitor/reitoria-informa/linhadireta/ linha_direta 46.htm

9. Albaño M. Dívida "estrangula" hospitais universitários federais. FolhaOnline [periódico na Internet] 2002. [acessado 2005 jun 15]. Disponível em: http:/ /www1.folha.uol.com.br/folha/educacao/ult305 u11911.shtml

10. Silva EP, Costa OS, Morgan BF. Aplicabilidade das informações de custo em Hospitais Universitários: o caso do Hospital Universitário de Brasília. In: Anais do XI Congresso Brasileiro de Custos; 2004; Porto Seguro (BA). [CDROM]

11. Verry D, Davies B. University costs and outputs. New York: Elsevier Scientific Publishing Company, Inc.; 1976.

12. Gander JP. Academic research and teaching productivities: a case study. Technological Forecasting and Social Change. Technological Forecasting and Social Change 1995; 49(2):311-319.

13. Sloan FA, Feldman RD, Steinwald AB. Effects of teaching on hospital costs. J. Health Econ. 1983; 2:1-28.

14. Hosek JR, Palmer AR. Teaching and hospital costs: the case of radiology. Journal of Health Economics 1983; 2:29-46.

15. Jones RF, Korn D. On the cost of educating a medical student. Academic M edicine 1997; 72(3):200-210.

16. Almeida MGM, Hajj ZS. M ensuração e avaliação do ativo: uma revisão conceitual e uma abordagem do goodwill e do ativo intelectual. Caderno de Estudos 1997; 9(16):66-83.

17. Brooking A. Intellectual capital: core asset for the third millennium enterprise. New York: International Thomson Business Press; 1996.

18. Sveiby KE. The New Organizational Wealth: managing and measuring knowledge based assets. San Francisco: Berrett-Koehler Publishers, Inc.; 1997.

19. Nonaka I, Takeuchi H. Criação de conhecimento na empresa. Rio de Janeiro: Campus; 1997. 
20. Padoveze CL. Aspectos da gestão econômica do Capital Humano. Revista de Contabilidade do CRCSP 2000; 14:4-10.

21. Matheus LF. U ma análise da identificação e da gestão do capital intelectual nas usinas sucroalcooleiras e da prática dos princípios delineadores do conceito de avaliação de empresas na sua gestão econômica-financeira: um estudo exploratório em dez usinas paulistas [dissertação]. São Carlos (SP): Escola de Engenharia de São Carlos, USP; 2003.

22. Arnosti JC, Gil AL, Neumann RA. A mensuração do Capital Intelectual: desafio para a profissão contábil. In: Anais da XXV Conferência Interamericana de Contabilidade; 2003; Panamá.

23. Bontis N. Assessing knowledge assets: a review of the models used to measure intellectual Capital. Santa Clara, Califórnia: KM World; 2000.

24. Hendriksen ES, Van Breda M F. Teoria da contabilidade. São Paulo: Atlas; 1999.

25. Stewart TA. Capital intelectual: a nova vantagem competitiva das empresas. 7ạ ed. Rio de Janeiro: Campus; 1998.

26. Martins $E$, organizador. Avaliação de empresas: da mensuração contábil à econômica. São Paulo: Atlas; 2001.

27. Assaf N eto A. Finanças corporativas e valor. São PauIo: Atlas; 2003.

28. Martins E. Contribuição à avaliação do ativo intangível [tese]. São Paulo (SP): Faculdade de Economia, Administração e Contabilidade, Universidade de São Paulo; 1972.

29. Damodaran A. A face oculta da avaliação. São Paulo: Makron Books; 2002.

30. Assaf N eto A. Estrutura e análise de balanços. 7ạ ed. São Paulo: Atlas; 2002.

31. Olak PA. Bases para a eficácia na aplicação do contrato de gestão nas organizações sociais brasileiras [tese]. São Paulo (SP): Faculdade de Economia, Administração e Contabilidade, Universidade de São PauIo; 2000.

32. Pereira CA. Avaliação de resultados e desempenhos. In: Catelli A. Controladoria: uma abordagem da gestão econômica. São Paulo: Atlas; 1999.

33. Ross SA, Westerfield RW, Jaffe JF. Administração financeira. São Paulo: Atlas; 1995.

34. Rappaport A. Gerando valor para o acionista. São Paulo: Atlas; 2001.

35. Araujo AM P. Ajustes na contabilidade tradicional para uma contabilidade baseada em valor [tese]. São PauIo (SP): FEA-USP; 2002.

36. Young SD, O'Byrne S. EVA e Gestão Baseada em Valor. Porto Alegre: Bookman; 2002.

Artigo apresentado em 08/05/2007

Aprovado em 14/12/2007

Versão final apresentada em 11/02/2008 